\title{
嫦娥三号着陆器推进系统关键技术 及飞行性能分析
}

金广明，曹伟*，魏彦祥，刘锋，王畋，陈剑

上海空间推进研究所, 上海 201112

*E-mail: cwi0211@sina.com

收稿日期: 2014-01-16; 接受日期: 2014-03-03

国家中长期科技发展规划重大专项资助项目

摘要本文结合嫦娥三号探测器主要任务特点, 简要介绍了推进系统的方案、组成、原理、 关键技术及解决措施, 重点对首次飞行试验验证情况和推进系统性能进行了全面分析, 结果表 明: 推进系统功能正常、工作可靠, 性能优良, 关键技术得到验证, 飞行试验取得圆满成功.

关键词

嫦娥三号

推进系统

深空探测

\section{1 引言}

嫦娥三号探测器于北京时间 2013 年 12 月 2 日 01 时 30 分由长征三号乙运载火箭从西昌卫星发射中 心发射升空, 经 2 次中途修正、 1 次近月制动和 1 次 环月变轨, 于 2013 年 12 月 14 日 21 时 12 分, 在月球 虹湾地区成功软着陆. 2013 年 12 月 15 日 23 点 47 分 左右, 着陆器与巡视器成功进行互成像试验, 标志着 嫦娥三号任务取得圆满成功.

嫦娥三号探测器经火箭发射段、地月转移段、环 月段和着陆下降段飞行后, 成功软着陆. 推进系统是 嫦娥三号探测器的关键分系统之一, 承担了探测器 飞行全过程姿态控制和轨道控制全部动力, 其工作 将直接影响任务的成败. 嫦娥三号探测器完全不同 于以往的嫦娥一号、嫦娥二号卫星 ${ }^{[1 \sim 3]}$, 其技术跨度 大、要求高、难度大、风险大, 这也决定了推进系统 具有要求高、技术新、难度大、复杂度高、风险高的 特点, 研制期间攻克了一系列关键技术. 本文重点介 绍了推进系统研制中的关键技术以及飞行试验结果.

\section{2 推进系统设计基本方案}

\section{1 系统基本方案及组成}

采用 $\mathrm{MMH} / \mathrm{MON}-1$ 双组元推进剂挤压式姿轨控 统一推进系统, 如图 1 所示. 增压氦气它存在 2 只高 压气瓶内; 4 只等容积金属隔膜咜箱对称布置, 分别 贮存燃料和氧化剂，最大可携带 $2600 \mathrm{~kg}$ 推进剂; 1 台 $7500 \mathrm{~N}$ 变推力轨控发动机位于着陆器中心, 为探测 器提供地月转移轨道变轨、近月制动及着陆下降过程 减速、悬停的轨控动力; 16 台 $150 \mathrm{~N}$ 和 12 台 $10 \mathrm{~N}$ 推 力器按相同功能分为 2 个分支, 安装于着陆器四周, 为探测器在轨飞行和着陆下降过程提供姿态控制、中 途修正、环月变轨、平移等动力.

推进系统分增压氦气输送、推进剂输送、推进剂 利用和驱动控制电路 4 大部分. 增压氦气输送部分由 气瓶、电爆阀、减压阀、气路自锁阀、安全阀及管路 等组成, 提供败箱工作的挤压气体和气动阀门的驱 动气体; 推进剂输送部分由咜箱、液路自锁阀、膜片 阀及管路等组成，用于咜存和供应发动机工作所需

引用格式: 金广明, 曹伟, 魏彦祥, 等. 嫦娥三号着陆器推进系统关键技术及飞行性能分析. 中国科学: 技术科学, 2014, 44: 385-390 Jing G M, Cao W, Wei Y X, et al. Key technologies and flight performance analysis for Chang'E-3 lunar lander propulsion system (in Chinese). Sci Sin Tech, 2014, 44: 385-390, doi: 10.1360/092014-44 


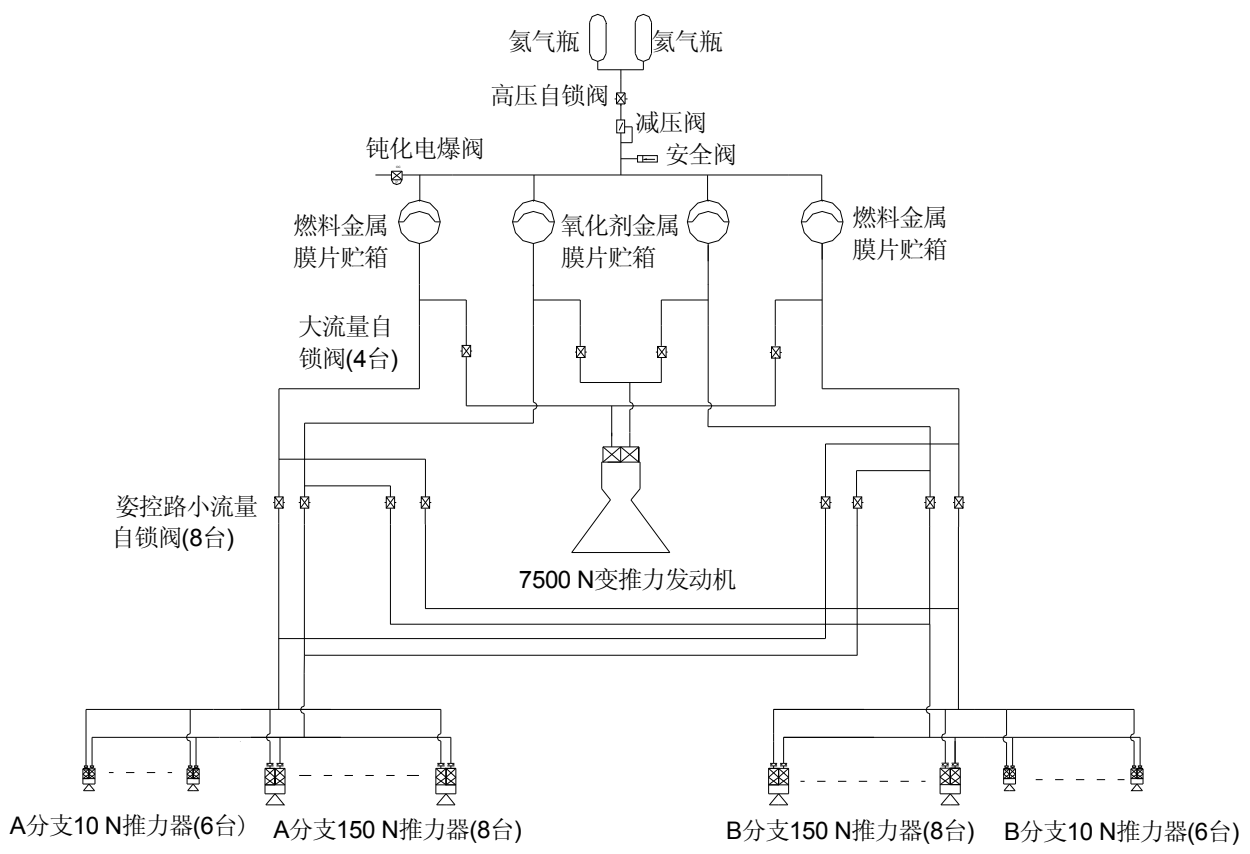

图 1 嫦娥三号着陆器推进系统原理图

推进剂; 推进剂利用部分由 $7500 \mathrm{~N}$ 变推力发动机、 $150 \mathrm{~N}$ 推力器及 $10 \mathrm{~N}$ 推力器等组成, 提供探测器飞行 全过程姿态控制和轨道控制全部动力; 驱动控制电 路由推进配电盒、推进线路盒、各类电磁式阀门、步 进电机、压力传感器等组成, 用于接收 GNC、数管、 测控系统控制指令, 实现设备供电控制和阀门、电机 的驱动控制, 以及压力传感器、触点开关、电压量遥 测采集.

\section{2 系统工作原理及工作模式}

器箭分离后, 打开气路电爆阀和高压自锁阀, 氦 气经减压阀减压后同步进入 4 只咜箱气腔(金属隔膜 前), 使隔膜变形移动, 并紧压于推进剂液体上. 当咜 箱增压压力达到约 $0.7 \mathrm{MPa}$ 时, 败箱出口膜片阀自行 打开, 燃料和氧化剂充填至液路自锁阀前, 继续增压 直至稳定在约 $1.95 \mathrm{MPa}$. 打开姿、轨控路液路自锁阀, 完成下游管路充填后, 各发动机即可按控制要求进 行工作. $7500 \mathrm{~N}$ 发动机分固定推力和变推力二种模式, 固定推力模式多采用 $7500 \mathrm{~N}$ 推力工况工作, 也可在 $5000 \mathrm{~N}$ 或更低推力工况工作; 变推力模式采用 7500 或 $5000 \mathrm{~N}$ 推力工况起动后再进行推力调节, 采用步 进电机进行流量调节, 进而实现推力调节.
正常情况下, 推进系统全程均以恒压模式工作. 当它箱超压时, 可关闭气路高压自锁阀切断气瓶供 气，利用败箱内气体进行落压模式工作. 无论是姿控 工作还是轨控工作，4只陉箱均为同步输出，以保证 混合比稳定和并联穴箱消耗均衡. 由于 $7500 \mathrm{~N}$ 发动 机工作次数较少, 为防止长时间非工作期间发动机 泄漏使推进剂大量损失, 发动机关机后随即关闭上 游自锁阀切断推进剂供应, 确保密封可靠, 再次工作 前提前打开自锁阀沟通推进剂供应.

探测器着陆后，考虑到经历月面昼夜交替的大 范围温度变化, 为了着陆器的安全, 对推进系统实施 钝化处理, 将捾箱内剩余推进剂采用 $150 \mathrm{~N}$ 推力器点 火耗尽, 以及将贮箱、气瓶内氦气进行排空.

\section{3 推进系统主要任务特点、设计关键技术 及解决措施}

\section{1 主要任务特点}

嫦娥三号着陆器飞行过程分火箭发射段、地月转 移段、环月段和着陆下降段. 各飞行阶段推进系统主 要任务特点如下.

1) 在火箭发射段, 经历火箭飞行过程中的力学 
环境, 由于推进系统重量大、尺寸大、管路复杂以及 组件安装方式特殊等, 对陉箱、气瓶、7500 N 发动机 等大尺寸部件的结构刚度、强度要求高;

2) 地月转移段和环月段飞行时间长, 空间环境 复杂, 对减压阀、推力器、电子设备等要求长寿命可 靠工作; $7500 \mathrm{~N}$ 发动机多次点火工作对轨道控制和推 进剂消耗量影响大, 对比冲性能、推力偏差和混合比 偏差控制要求高;

3) 着陆下降段推进系统工作最为复杂, 工况变 化范围大. 轨控发动机连续工作约 $700 \mathrm{~s}$, 既有 7500 $\mathrm{N}$ 额定推力工况长程工作, 又有多种推力快速调节工 作; 贮箱要适应探测器平移侧向过载、大小流量迅速 转换、消耗末期大流量防漩、并联均衡排放等要求.

\section{2 设计关键技术及解决措施}

鉴于探测器总体对推进系统的高性能、高可靠要 求和特殊构型约束, 给推进系统的设计带来巨大难 度, 由此带来诸多设计关键技术, 主要包括以下几个 方面.

\subsection{1 系统减重优化技术}

推进系统具有总冲大、陉箱工作压力高、推进剂 流量大等特点, 但对推进系统结构质量要求苛刻(不 大于 $295 \mathrm{~kg}$ ). 为此, 采取了多种减重设计措施, 如 $\mathrm{T} 700$ 缠绕金属隔膜穴箱技术; T1000 缠绕高压气瓶技 术; 一体化、大流量轨控自锁划技术; 轻质复合材料 姿控推力器机架技术; 各类小型化、轻质化阀门技术; 铝镁合金电子设备壳体技术; $7500 \mathrm{~N}$ 发动机薄壁喷管 加工技术等.

\subsection{2 并联金属隔膜贮箱均衡排放控制技术}

针对金属隔膜咜箱一次使用的特殊性, 为保证 并联金属隔膜贮箱排放均衡度小于 $3 \%$ 的要求, 采取 20\%预排放压差数据匹配配对, 尽量保持并联贮箱压 差基本一致. 地面试验验证结果表明, 20\%预排放不 影响隔膜可靠工作, 20\%预排放压差能够良好地表征 全程排放压差特性, 是解决并联均衡排放的有效措 施. 同时, 结合配对贮箱 $20 \%$ 预排放压差数据的微小 差异, 再通过管路节流孔板进行流阻精确匹配调试, 以保证两路流量一致. 通过多轮推进系统地面试验 验证, 并联贮箱排放均衡性可满足总体 3\%指标要求, 实际达到了优于 $2 \%$ 水平 ${ }^{[4-6]}$.

\subsection{3 轻质量、高挤出效率、无晃动金属隔膜贮箱 技术}

嫦娥三号推进系统选用了适应大流量、侧过载、 气液物理隔离、无晃动的金属隔膜式拒箱, 但常规金 属隔膜式败箱存在结构质量重、挤出效率低的缺点. 为了降低拒箱结构质量, 采用铝合金内祄壳体外缠 绕 T700 碳纤维, 较常规全金属隔膜它箱减重 50\%以 上, 但薄厚度、变厚度的缠绕层存在与内祄层变形匹 配、层间分离等问题. 经过攻关阶段试验验证, 疲劳、 爆破强度和结构重量等性能均达到预定要求. 为了 解决金属隔膜近箱挤出效率偏低问题(一般不超过 98\%), 通过多轮对隔膜优化改进，提高了隔膜与壳 体的匹配性, 经试验验证, 挤出效率能够满足 $\geqslant 99 \%$ 的要求, 最高达到 $99.3 \%$.

\subsubsection{N 发动机参数精确控制技术}

由于结构包络、系统质量、败箱压力和姿控推力 器工况匹配性等限制, 对 $7500 \mathrm{~N}$ 发动机入口压力严 格约束不大于 $1.7 \mathrm{MPa}$, 使发动机性能提高受到制约, 如发动机室压、喷管面积比选取, 直接影响比冲性能 [7]. 考虑到 $7500 \mathrm{~N}$ 发动机在额定推力工况消耗近 $85 \%$ 的推进剂, 推力精度对轨道控制影响重大, 需要 控制发动机额定工况下的推力、混合比精度. 主要采 取两方面措施: 一是按 1:1 轨控管路系统状态进行流 阻调试; 二是根据 $7500 \mathrm{~N}$ 发动机热标试车结果, 按 $1.7 \mathrm{MPa}$ 入口压力进行单机流阻调试. 经推进系统全 系统热试车验证, 额定推力工况下 $7500 \mathrm{~N}$ 发动机推 力和混合比偏差均可控制在 $1 \%$ 以内.

\subsubsection{0 $\mathrm{N}$ 发动机精细、快速变推力调节控制 技术}

嫦娥三号推进系统的 $7500 \mathrm{~N}$ 发动机除具备 7500 $\mathrm{N}$ 额定推力工况定推力工作外, 其变推力工作是极其 重要的特征, 需具备 5000 1500 N 范围内精确、快速、 连续可变推力能力. 为了提高 $7500 \mathrm{~N}$ 发动机的精确、 快速推力调节性能, 步进电机采用两细分、高频率闭 环控制方案, 步进控制频率达到 $1000 \mathrm{~Hz}$, 单步推力 分辨率达到 $6.25 \mathrm{~N} /$ 步的水平, 保证了着陆下降段推 力调节的快速、精确.

\subsection{6 系统可靠性、安全性设计技术}

系统结构重量严格限制了系统先余设计程度. 
基于 FMEA 分析结果, 对影响重大的关键环节采取 了有限攵余设计, 以提高系统可靠性, 如 28 台姿控 推力器分 $\mathrm{A}, \mathrm{B} 2$ 分支, 实现故障重组; 推进线路盒采 用主、备机咒余设计, 可实现切换; $7500 \mathrm{~N}$ 发动机步 进电机采用主、备几余绕组, 开、关机采用互锁控制, 确保状态唯一; 使用膜片阀减少电路控制环节; 采用 双道密封安全阀防咜箱超压; 并联电爆阀确保气路 可靠沟通等. 通过系统优化设计, 有效解决了重量与 可靠性的矛盾，规避或降低了系统风险.

\subsection{7 推进系统月面钝化技术}

着陆后, 需对推进系统进行钝化处理, 以确保着 陆器月面长期工作安全. 由于钝化过程存在较多的 不确定因素, 尚无可直接借鉴的成熟经验, 更难以地 面试验验证, 存在一定风险, 如大范围混合比变化是 否引起发动机烧蚀, 2 种组元耗尽不同步是否引起冻 结或倒窝引起爆燃等. 合理设计钝化方案和程序是 关键. 嫦娥三号飞行结果表明, 采用 4 台 $150 \mathrm{~N}$ 推力 器同步点火、任一组元管路压力降至约 $0 \mathrm{MPa}$ 时实施 关机的方案是合理、安全和可控的.

\section{4 飞行试验主要结果分析}

\section{1 地月转移飞行段}

2013 年 12 月 2 日 15 时 50 分, 完成第一次中途 修正, 采用 8 台 $150 \mathrm{~N}$ 推力器同时工作, 点火 $25.1 \mathrm{~s}$, 经轨道、 GNC 加速度计标定, 单台推力器平均推力 $155 \mathrm{~N}$ ，与预计 $154 \mathrm{~N}$ 一致; 2013 年 12 月 3 日 16 时 20 分, 完成第二次中途修正, 采用 $7500 \mathrm{~N}$ 发动机以 额定推力工况工作, 点火 $10.4 \mathrm{~s}$, 稳定段平均推力为 7492.4 N. 两次中途修正均达到预定目标, 并获得了 $7500 \mathrm{~N}$ 发动机在轨推力性能, 为近月制动和动力下 降制定轨控策略提供了依据. 通过 $7500 \mathrm{~N}$ 发动机约 $10 \mathrm{~s}$ 点火工作, 不仅检验了发动机工作状况, 也证明 实施在轨推力标定是必要和可行的. 图 2 为第二次中 途修正 GNC 加速度计估算的推力变化曲线.

\section{2 环月飞行段}

2013 年 12 月 6 日 17 时 47 分, 探测器成功完成 一次近月制动后进入环月轨道, $7500 \mathrm{~N}$ 发动机额定推 力工况点火工作 $360.6 \mathrm{~s}$, 平均推力为 $7522.8 \mathrm{~N}$, 与第 二次中途修正稳定段推力基本一致. 图 3 为近月制动

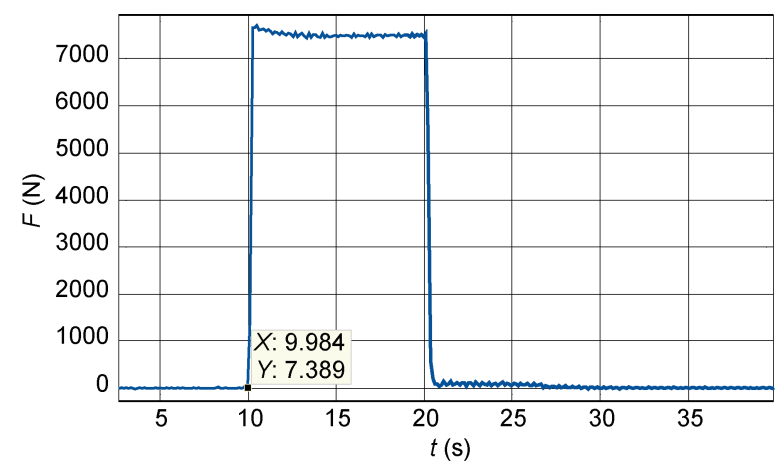

图 2 (网络版彩图)第二次中途修正 $7500 \mathrm{~N}$ 发动机推力 变化曲线

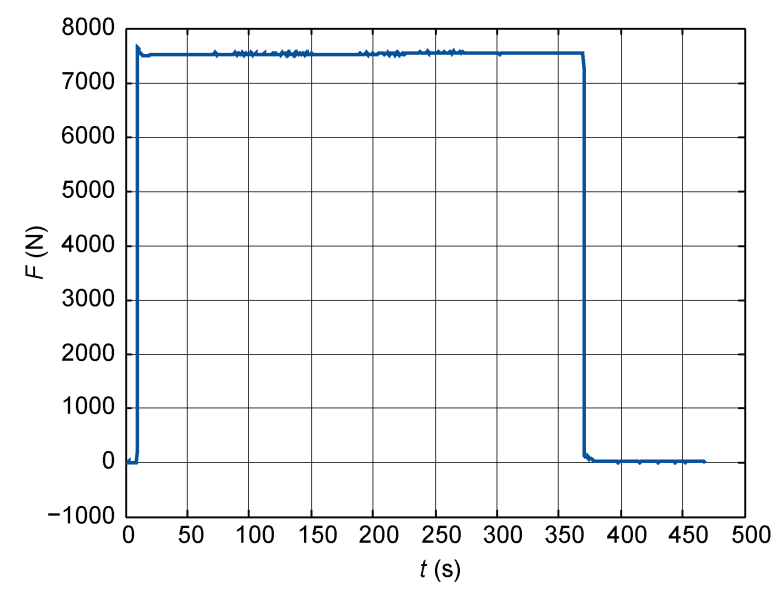

图 3 (网络版彩图)近月制动 $7500 \mathrm{~N}$ 发动机推力变化曲线

段 GNC 加速度计估算的推力变化曲线. 2013 年 12 月 10 日 21 时 37 分, 探测器成功完成一次环月降轨控制, 采用 8 台 $150 \mathrm{~N}$ 推力器点火工作, 共点火 $39.7 \mathrm{~s}$, 单 台推力器平均推力约为 $157.4 \mathrm{~N}$.

\section{3 动力下降阶段}

2013 年 12 月 14 日 21 时, 探测器从近月点 $15 \mathrm{~km}$ 处开始进行动力下降, $7500 \mathrm{~N}$ 发动机以额定推力工况 点火 $480 \mathrm{~s}$ 完成主减速段工作, 紧接着以变推力模式 连续工作 $204 \mathrm{~s}$, 依次完成了快速调整段、接近段、悬 停段、避障段和缓速下降段的工作, 图 4 给出了动力 下降段 GNC 加速度计估算的推力曲线和根据步进电 机步数换算的变推力曲线, 两者变化规律完全一致.

\section{4 月面工作阶段}

嫦娥三号探测器着陆后, 于 2013 年 12 月 24 日 22 时 26 分开始进行推进系统针化工作, 4 台 $150 \mathrm{~N}$ 推 力器连续工作约 $16 \mathrm{~min}$, 当氧化剂姿控管路压力接 


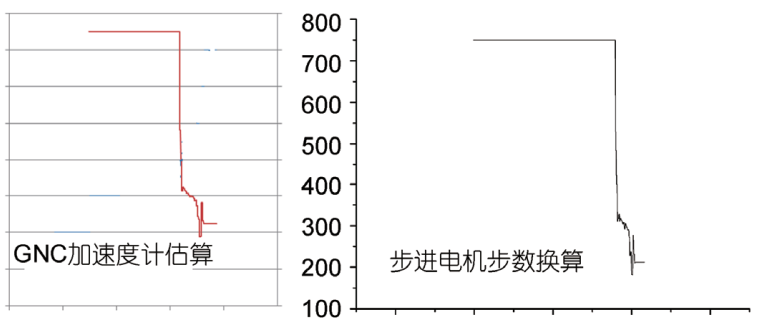

图 4 (网络版彩图)动力下降段变推力曲线

近 $0 \mathrm{MPa}$ 时, $150 \mathrm{~N}$ 推力器关机, 推进剂钝化完成, 之 后, 打开钝化电爆阀, 直至气瓶和它箱内氦气排空, 完成全部钝化工作. 推进剂钝化过程姿控管路压力 变化曲线如图 5 所示.

\section{5 推进系统主要性能分析}

嫦娥三号飞行试验对推进系统的工作进行了全 面验证, 飞行全程系统及各组件工作正常、可靠, 各 阶段飞行时序正确、参数稳定, 与地面系统试车结果 吻合. 下面就系统主要参数分析如下.

减压阀出口压力性能影响各发动机推力精度. 3 次 $7500 \mathrm{~N}$ 额定推力工况工作时, 减压阀出口压力稳 定在 $1.837 \mathrm{MPa}$, 与地面调试值 $1.85 \mathrm{MPa}$ 一致. 纯姿 控工作模式下, 减压阀出口静压稳定在 $1.924 \sim 1.937$ $\mathrm{MPa}$, 略优于 $1.96 \sim 1.98 \mathrm{MPa}$ 地面调试值, 对 150,10 $\mathrm{N}$ 推力器工作可靠性更为有利.

$7500 \mathrm{~N}$ 发动机入口压力直接与推力、混合比相 关, 飞行结果表明, $7500 \mathrm{~N}$ 推力工况下, 燃料和氧化 剂入口压力均保持 $1.695 \mathrm{MPa}$, 与系统调整值 1.7 $\mathrm{MPa}$ 一致, 有效保证了发动机推力和混合比精度.

咜箱压差变化的一致性是影响并联咜箱均衡排 放性能的关键因素之一. 图 6 给出了近月制动段和着

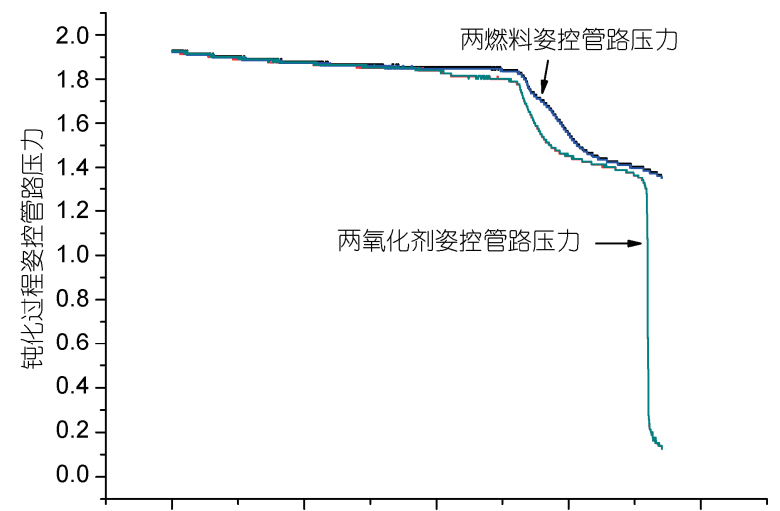

图 5 (网络版彩图)钝化工作时姿控管路压力变化曲线

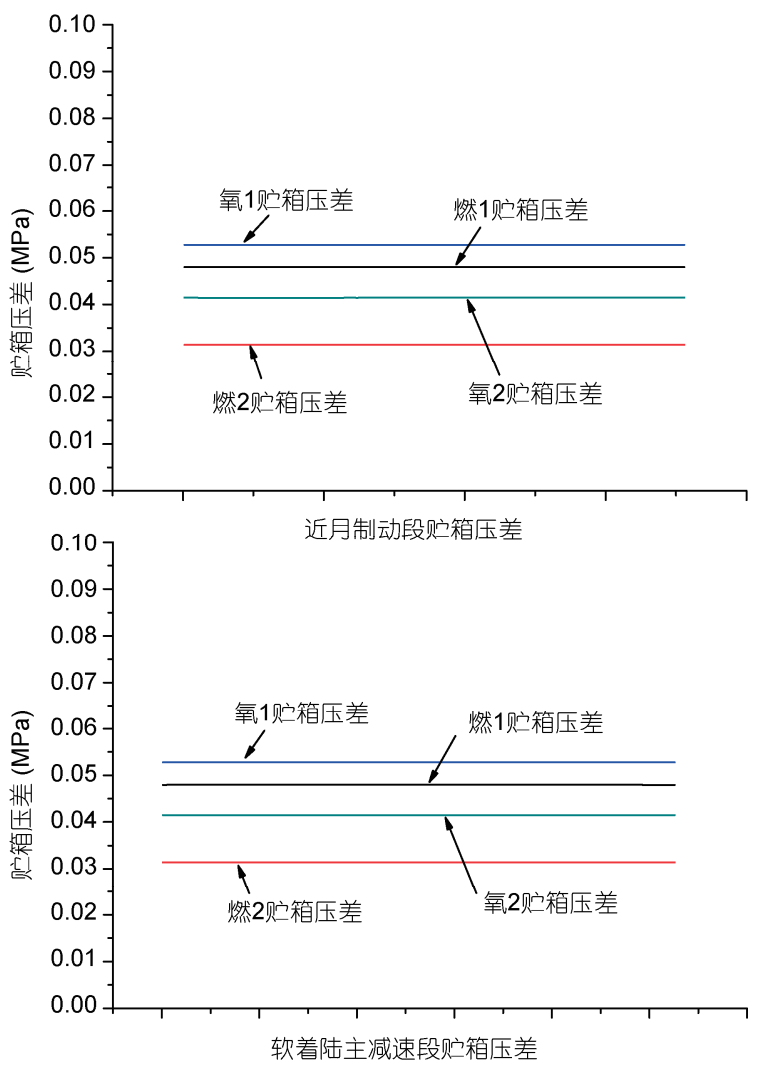

图 6 (网络版彩图)飞行过程贮箱压差曲线

陆下降主减速段 4 只咜箱压差的变化曲线, 从图中可 以看出, 各咜箱压差变化基本一致. 因 $7500 \mathrm{~N}$ 发动机 关机时推进剂剩余较多，咜箱尚未工作到末期，压差 基本未升高，因此未出现并联排放等待现象，间接证 明了全程飞行并联咜箱排放均衡性良好. 至推进剂针 化工作到 648 和 $664 \mathrm{~s}$ 时, 两氧化剂咜箱和两然料咜 箱压差比较值出现拐点, 据此计算飞行过程中氧化剂 咜箱最大消耗不均衡度为 $1.26 \%$, 燃料咜箱最大消耗 不均衡度为 $1.6 \%$, 满足不大于 $3 \%$ 的技术指标要求, 与推进系统 03,04 次地面全系统试车结果相当.

推进系统钝化工作时, 4 个咜箱压差依次跳变到 0.4 MPa，此压差对应咜箱排放率不低于 99.0\% . 根据 各咜箱压差起跳时间, 分析飞行过程中平均消耗混 合比约为 1.645 , 与地面加注混合比 1.64 基本一致, 满足 $1.65 \pm 0.05$ 的技术指标要求.

\section{5 结论}

嫦娥三号飞行试验数据结果表明：推进系统功 
能正常、工作可靠, 各项性能参数优良, 达到或优于 总体指标要求; 系统设计方案、关键技术均得到全
面、有效验证; 推进系统顺利完成了全部飞行试验任 务，取得圆满成功.

\title{
参考文献
}

1 叶培建. 嫦娥一号卫星的技术进步点. 中国航天, 2008, 4: 9-12

2 叶培建, 黄江川, 张廷新. 嫦娥二号卫星技术成就与中国深空探测展望. 中国科学: 技术科学, 2013, 43: 467-477

3 梁军强, 王晓否, 宋涛. 嫦娥二号卫星推进系统拓展任务性能分析. 中国科学: 技术科学, 2013, 43: 733-738

4 钱海涵. 并联咜箱不平衡输出及其解决途径. 上海航天, 2000, 1: 8-11

5 刘锋, 周进. 金属膜片陉箱推进剂消耗不平衡分析. 火箭推进, 2006, 32: 28-31

6 魏彦祥，赵京. 用于并联金属膜片咜箱均衡排放的一种控制方法. 空间推进, 2011, 5: 5-8

7 曹伟. 某变推力推进系统参数适应性分析. 空间推进, 2012, 6: 1-3

\section{Key technologies and flight performance analysis for Chang'E-3 lunar lander propulsion system}

\author{
JIN GuangMing, CAO Wei, WEI YanXiang, LIU Feng, WANG Rui \& CHEN Jian
}

Shanghai Institute of Space Propulsion, Shanghai 201112, China

Combining with the main characteristics of flight task, this paper describes the program, compositions, principle, key technologies and solutions of Chang'E-3 lunar lander propulsion system briefly and focuses on a comprehensive analysis of the first flight experiment validation and propulsion system performance. The results show that the propulsion worked properly and reliably with excellent flight performance, the key technologies were validated and the flight experiment achieved a great fully success.

\section{Chang'E-3, propulsion system, deep-space exploration}

doi: 10.1360/092014-44 